\title{
DIVERSIDADE E PERENIDADE DA VIOLEENCIA NO BRASIL
}

\section{- Fernando de Oliveira dos Santos ${ }^{1}$}

Universidade Estadual Paulista "Júlio de Mesquita Filho"

Assis - São Paulo - Brasil

Resenha do Livro: PRIORE, Mary del $\mathcal{E}$ MÜLLER, Angélica (org.). História dos crimes e da violência no Brasil. São Paulo: Editora Unesp, 2017.

O lançamento desta coletânea de ensaios, organizada por duas prestigiadas historiadoras, não poderia ter chegado em um contexto mais fecundo. A dimensão que o problema da criminalidade urbana violenta tem alcançado nos últimos anos tem incitado estudiosos de diferentes áreas a buscarem explicações para tal fenômeno. Nesse sentido, essa obra deve ser percebida como uma importante contribuição para refletirmos sobre essa candente temática a partir de uma perspectiva histórica.

Os dezesseis capítulos reunidos nesta antologia têm como mote a análise de vários crimes, abrangendo diversas modalidades de violência, desde os primórdios do período colonial até a época hodierna. Assim, os artigos

\footnotetext{
1 Mestrando do Programa de Pós-Graduação em História da Faculdade de Ciências e Letras da Unesp, campus de Assis. Área de concentração: História e Sociedade; linha de pesquisa: Cultura, Historiografia e Patrimônio. E-mail: fernandobraudel@hotmail.com.
} 
abordam eventos históricos nos quais diferentes formas de delito e violência se expressaram. Seja no âmbito público ou privado, as duas esferas onde sempre se notou uma relação porosa, crimes envolvendo homofobia, intolerância religiosa, violência estatal, corrupção, entre outros, são examinados. Os autores dos artigos possuem formação em diversas áreas (Direito, Sociologia, Educação Física, Antropologia, Psicologia e História). No entanto, a maioria dos pesquisadores que participaram dessa obra são historiadores.

Não obstante o fato dos ensaios tangenciarem eventos e situações em diferentes espaços e temporalidades da história do Brasil, as organizadoras da coletânea admitem que haja um eixo analítico comum para enfocar os diversos casos narrados. Para elas "O fio condutor está centrado na ideia de como o crime e o emprego da violência fizeram e fazem parte da nossa sociedade" (p. 8). Assim, pretende-se descrever de forma sucinta os aspectos essenciais dos 16 capítulos com o intuito de, ao final, refletir criticamente sobre o fio condutor da obra na perspectiva das autoras.

No primeiro capítulo, o historiador Paulo de Assunção narra um dos episódios mais sangrentos e nefastos envolvendo o empreendimento de catequização da América portuguesa pela Companhia de Jesus. O contexto histórico remete ao Concílio de Trento (1548-1563) e às acirradas disputas entre católicos e protestantes desencadeadas tanto no "Velho" quanto no Novo Mundo. Em 1570, um grupo de quarenta jesuítas liderados pelo padre português Inácio de Azevedo partiu para as "terras do Brasil" para evangelizar os povos ameríndios. Contudo, ainda na região das ilhas Canárias, a embarcação Santiago foi interceptada e atacada por calvinistas franceses.

Um dos aspectos mais destacados no texto é a extrema violência empregada pelos corsários franceses após abordarem o barco dos jesuítas e dominarem rapidamente todos os missionários. A superioridade bélica e numérica foi preponderante para a vitória dos calvinistas. Eles estavam distribuídos numa frota composta por cinco embarcações, somando cerca de trezentos homens munidos de canhões, capacetes, espadas e outros artefatos bélicos. Por outro lado, apesar da valentia, os parcos armamentos dos portugueses impossibilitavam qualquer chance de resistência. Assim, "A crueldade preponderou. Muitos, trespassados por espadas, agonizavam no convés até serem lançados no mar" (p. 23). Além disso, tomados por uma intensa cólera, os protestantes ainda destruíram todos os objetos devocionais católicos como imagens, breviários e outros objetos. Esta agressividade extremada, segundo Gonçalves, evidenciava “(...) a aversão dos calvinistas aos jesuítas, em parte devido à atuação da Companhia de Jesus na perseguição aos protestantes no território europeu" (p. 25). 
No segundo capítulo, Luiz Mott conta o desfecho de duas devassas envolvendo um índio e um jovem escravo acusados de cometerem sodomia, ambas no século XVII. Esses dois episódios, conforme o autor, podem ser entendidos como a gênese da homofobia no Brasil. O primeiro caso ocorreu no contexto da fundação da França Equinocial no Maranhão. Em 1613, um índio tupinambá foi condenado à morte na boca de um canhão após ser incriminado por capuchinhos franceses pela prática de homoerotismo. Após ser denunciado e capturado, o ameríndio reconheceu publicamente que cometeu o pecado da sodomia. Com isso, procedeu-se ao julgamento na presença dos missionários franceses e também dos indígenas e, logo em seguida foi aplicada a sentença. O nativo foi colocado na boca de um canhão que foi disparado por um algoz da própria tribo. Com o tiro, seu corpo foi dividido em duas partes, caindo uma ao pé da muralha e outra no mar.

O segundo caso, ocorreu no Sergipe em 1678, quando um moleque escravo foi açoitado até a morte por seu senhor. Esse fato aconteceu após o capitão Pedro Gomes, muito conhecido na região por ter relações homossexuais com vários cativos, ter solicitado a seu vizinho Luís Gomes um escravo para certa jornada. Todavia, quando retornaram, o proprietário notou que seu moleque estava diferente, pois vestia umas ceroulas. Ao questioná-lo, supondo que seu escravo havia furtado essas peças, o negro não quis responder. Por esse motivo, seu senhor mandou açoitá-lo e durante o suplício o jovem escravo confessou que ganhou aquelas ceroulas do capitão Pedro Gomes como "recompensa" após ter com ele relações homoeróticas. A partir de então, o proprietário intensificou o martírio contra seu cativo levando-o a morte.

Segundo Mott, a extrema crueldade verificada em ambos os casos sinaliza o alto grau de homofobia que impregnava o imaginário coletivo. $\mathrm{O}$ homoerotismo era severamente combatido pela doutrina cristã, entre outros motivos, porque “(...) além de desperdiçar a semente da tão necessária reprodução dos novos cristãos, tinha como incontrolável consequência a efeminação de seus praticantes, enfraquecendo sua valorizada virilidade" (p. 47).

No terceiro capítulo, Randolpho Corrêa e Jonis Freire recuperam vários elementos da legislação penal brasileira em vigor no século XIX, revelando a cotidianidade dos crimes violentos. Conforme os autores, nesta sociedade escravista "Homicídios, suicídios, infanticídios, roubos, estupros, castigos físicos e outros tipos de violência física foram muitos comuns" (p. 66). Os dois historiadores demonstram o quanto a sociedade era permeada por conflitos e tensões que ocorriam tanto de forma vertical quanto horizontal no âmbito rural ou urbano. Assim, eles procuram descontruir a equivocada percepção de que os crimes e a violência neste contexto se restringiam a senhores e escravos. 
No quarto capítulo, Vitor Izecksohn, tendo como pano de fundo a Guerra do Paraguai (1864-1870), aborda os percalços e as dificuldades enfrentadas pelas autoridades imperiais durante o processo de recrutamento de tropas. Neste contexto, os investimentos empregados pelo Estado brasileiro para provisões, equipamentos e alojamentos eram insuficientes para atender a todas as demandas. Este quadro desolador desestimulava o engajamento de potenciais voluntários. Diante disso, o governo solicitou o apoio das autoridades particulares locais para promover o recrutamento forçado de seus clientes e protegidos. Entretanto, conforme o autor, essa medida foi interpretada por muitos como uma atitude invasiva do governo imperial, provocando resistências e gerando reações hostis ao trabalho dos recrutadores.

O prolongamento inesperado do tempo da guerra e a inexistência de um aparato de vigilância adequado motivaram inúmeros ataques violentos às cadeias com o objetivo de resgatar presos, muitas vezes com apoio dos chefes locais.

No quinto capítulo, o historiador Vitor Melo disseca o processo de desenvolvimento das touradas e do turfe no Rio de Janeiro a partir da segunda metade do século XIX. Ele explica como os espetáculos públicos em torno dessas modalidades esportivas engendravam tensões e conflitos de diversas ordens. O autor identifica os fatores que instigavam os espectadores, especialmente dos segmentos mais pobres, a depredarem as instalações da arena, provocando em seguida atritos com as forças policiais. É destacado como o processo de estigmatização das corridas de touros estava relacionado ao aumento das preocupações com a cena pública, já que essa prática desportiva “(..) cada vez mais era considerada inadequada para uma cidade que alguns pretendiam ver civilizada" (p. 124).

No sexto capítulo, Daniel Faria analisa a temática do crime na literatura brasileira a partir de duas obras nacionais produzidas nos anos 1930 durante a era Vargas: Angústia (1936) de Graciliano Ramos e Os ratos (1935) de Dyonélio Machado. O historiador identifica os fatores que explicam a incorporação do crime ao campo literário. Ele pontua que este mote está umbilicalmente associado à expansão da urbanização. Dentro dessa nova configuração social o crime destaca-se por uma questão de toda trama narrativa: ele proporciona fascínio, pois “(...) traz um elemento de surpresa, choque, que coloca o enredo em movimento, dando-lhe dramaticidade" (p. 155).

Em relação ao estilo da escrita de Graciliano Ramos, Faria considera que sua obra literária se caracteriza por uma espécie de investigação psicológica. Para ele, fica nítida em Angústia a preocupação do escritor em revelar as sutilezas psíquicas dos personagens. Outro aspecto marcante é sua predile- 
ção por enredos que contemplam casos extremos como violências, loucuras, alucinações etc. Este tipo de narrativa proporciona o "gozo espiritual" ao leitor, na medida em que o torna "(...) capaz de viver essas vidas alucinadas e criminosas, padecendo com elas - à distância" (p. 159).

Já na obra Os ratos de Dyonélio, o foco central de sua abordagem é a natureza do homicídio. Fundamentado na "psicologia do homem primitivo" o escritor defende a tese de que mesmo na modernidade o comportamento dos homicidas seria semelhante ao dos indivíduos de épocas primitivas. Na percepção de Dyonélio, segundo Daniel Faria, o crime "seria o resultado de que alguns indivíduos falhavam no caminho da civilização, desejando retornar ao estágio primitivo, quando não havia o conceito de delitos" (p. 168).

No sétimo capítulo, Wagner Pereira nos apresenta um painel muito detalhado do processo de apropriação da temática do crime pela mídia brasileira no período de 1961 a 2016. O historiador faz uma interessante digressão aos primórdios da TV no Brasil para explicar como, desde cedo, os crimes violentos foram sendo incorporados e manejados nas telenovelas com o intuito de cativar os telespectadores, garantindo elevados índices de audiência. Para o autor, no decorrer da trajetória da teledramaturgia, percebe-se a gestação de uma "cultura de mídia" que passa a ser massivamente consumida pela sociedade.

O telejornalismo foi o outro gênero televisivo esquadrinhado pelo autor em seu ensaio. Wagner Pereira analisa detidamente a influência dos programas "sensacionalistas" na construção das representações coletivas ao promover a "espetacularização da violência". Para ele "(...) os discursos dos telejornais policialescos acabam criando a ideia de que quem defende a população são as pessoas que agem com truculência, violência e arbitrariedade" (p. 230).

No oitavo capítulo, Angélica Müller analisa os desdobramentos da morte do estudante Edson Luís em 1968. Ela revela como este evento tornou-se um ponto de inflexão no percurso da ditadura militar. Um dos fatos destacados após o ocorrido foi a disputa pelo corpo do secundarista entre as autoridades do Estado de um lado e os estudantes da UNE de outro - situação que, a partir de então, seria recorrente neste período.

Outro momento examinado pela historiadora foi o das cenas impactantes que marcaram o velório de Edson Luís que contou com a participação de milhares de estudantes. Ela sublinha que a exposição do corpo ferido e a camiseta manchada de sangue aludiam à própria representação do suplício de Cristo. Além disso, nesta cerimônia fúnebre, verificavam-se objetos e símbolos representando não apenas um ritual religioso, mas também político. A bandeira nacional enrolada no caixão e os inúmeros cartazes nas mãos dos estudantes e em cima do corpo do estudante evidenciavam esta atmosfera. 
As incontáveis manifestações que irromperam em várias capitais e cidades do país, assim com a truculenta repressão policial, também foram abordadas. Segundo Müller, a morte do estudante em março de 1968 teve como principal desfecho o decreto do Ato Institucional (AI-5) em dezembro do mesmo ano. A partir de então “(...) os dispositivos de violência do Estado que já estavam sendo aprimorados foram acionados em sua máxima: a tortura institucionalizou-se como política para todos aqueles que praticassem atos contra o regime" (p. 244).

No nono capítulo, José César Coimbra nos apresenta um panorama bastante detalhado e atualizado sobre o combate a violência doméstica, examinando tanto o cenário nacional quanto o internacional. Entre outros enfoques, o psicólogo procura problematizar e responder questões candentes como as seguintes: O que se pode entender por violência contra mulher? Com a Lei Maria da Penha o que mudou nas possibilidades de garantia de direitos e responsabilização? Como a sociedade percebe o fenômeno da violência doméstica?

O autor observa como uma série de fenômenos no contexto hodierno tem contribuído para o aumento da sensibilidade social no que tange a essa temática. Ele sublinha o papel da mídia, especialmente das redes sociais, na tarefa de conscientização, denúncia e também na divulgação dos movimentos sociais. Todavia, apesar da crescente indignação da sociedade, Coimbra percebe um importante paradoxo: "maior visibilidade, ampliação, aperfeiçoamento do sistema de garantia de direitos e possibilidades de responsabilização e, no entanto, continuidade de tipos de violência e desigualdade que atravessam gerações" (p. 257).

No décimo capítulo, o assassinato da missionária Dorothy Stang em 2005 é o escopo da análise de Marcelo Timotheo da Costa. Ele insere este evento singular dentro de um quadro mais amplo para descortinar os fatores estruturais e históricos que condicionaram inúmeros homicídios na região norte e nordeste do Brasil.

Segundo o autor, o ativismo de Stang centrava-se na busca de soluções para três graves problemas estruturais na região norte: o da concentração de terras, o do trabalho semiescravo e o da exploração predatória do meio ambiente. Assim, ao defender com afinco ideias como a redistribuição de terras da União para a reforma agrária e criar o audacioso Projeto de Desenvolvimento Sustentável (PDS), a missionária passou a incomodar a elite local. Segundo Costa, a ideia do PDS “(...) com sua reivindicação da reforma na estrutura agrária e também por seu zelo ecológico - agregou inimigos de peso: latifundiários, proprietários de madeireiras e até comerciantes" (p. 294). 
No décimo primeiro capítulo, a intolerância religiosa no Brasil é o tema do ensaio de Quézia Brandão. Ela nos apresenta um panorama dos embates e polêmicas em torno deste problema social que tem afetado com maior recorrência os praticantes das religiões afro-brasileiras. Um dos tópicos mais fecundos do artigo é "Entre templos e terreiros: a construção da intolerância" em que a pesquisadora versa sobre as origens históricas do preconceito, discriminação e intolerância religiosa no Brasil. Brandão faz uma incursão ao período colonial para examinar a construção do imaginário e das representações coletivas, indicando neste processo a supremacia do catolicismo sobre as religiões de matriz africana e indígena, não obstante o sincretismo que se verificou no decorrer do tempo.

No décimo segundo capítulo, a historiadora Viven Ishac e a jurista Carolina de Campos Melo focalizam o desaparecimento de Rubens Paiva em janeiro de 1971, tendo como lastro as conclusões obtidas pela Comissão Nacional da Verdade (CNV). Este órgão foi instalado em 16 de maio de 2012 e encerrou seus trabalhos em 16 de dezembro de 2014. Sua principal incumbência foi investigar minuciosamente e esclarecer os crimes que atentavam contra os direitos humanos no período de 1946 a 1988.

A partir dos dados fornecidos pela CNV, as autoras elucidaram as circunstâncias que motivaram os agentes da ditadura a prenderem ilegalmente o deputado federal, um dos mais ferrenhos opositores ao regime. Elas revelaram como as múltiplas formas de tortura perpetradas contra Rubens Paiva provocaram sua morte e como seu corpo foi ocultado pelas instituições militares. Mais do que dissecar um caso particular isolado, o ensaio reconstitui toda uma conjuntura histórica marcada por graves violações dos direitos humanos, legitimadas por uma política de Estado. Assim, demonstrou-se que a crueldade cometida contra os presos políticos nos interrogatórios, os assassinatos e as falsas versões sobre o desaparecimento das vítimas do regime eram todas práticas institucionalizadas, amparadas pela "(...) participação coordenada de agentes em diferentes níveis hierárquicos e no exercício de funções distintas, organizadas sob a forma de cadeias de comando" (p. 340).

No décimo terceiro capítulo, Vitor de Angelo aborda a corrupção no Brasil, problematizando o modo como a população percebe este fenômeno. O horizonte de investigação fundamenta-se no diagnóstico de pesquisas recentes apontando que a corrupção é vista como o maior problema do Brasil. Segundo o sociólogo, este entendimento indica uma crescente indignação da sociedade com este problema e isso relaciona-se ao fato de que nos últimos anos, o combate a corrupção tem dominado a agenda da mídia, das instituições políticas e da sociedade civil organizada. A premissa do autor é que 
“(...) muitos podem ter a sensação de que esse é um problema recente, que começou há pouco tempo ou que se reduz ao governo e ao partido que está no poder" (p. 347). Assim, o cientista social procura demonstrar que a corrupção vigora no Brasil desde épocas remotas, estando presente não apenas no campo político, mas também em toda a esfera pública e privada.

No décimo quarto capítulo, Mauricio Murad analisa os escândalos de corrupção no futebol, especialmente envolvendo instituições como a Fifa e a CBF. O sociólogo investiga a influência das redes que articulam os interesses de várias entidades e atores em torno do futebol, abrangendo grandes corporações, empresários, dirigentes de clubes, federações, confederações etc. A constatação mais relevante de Murad refere-se a interface entre os diversos crimes praticados no âmbito do futebol e aqueles que são cometidos no contexto mais amplo da nossa sociedade. Crimes como sonegação, desvios, propinas, fraudes fiscais e eleitorais, lavagem de dinheiro, entre outros, permeiam toda nossa vida coletiva. "Portanto, os ilícitos no futebol brasileiro têm muita relação com a história e a cultura dos ilícitos de nossa sociedade. Os crimes que ocorrem no universo do futebol apontam para os crimes que ocorrem no conjunto da sociedade" (p. 389).

No décimo quinto capítulo, Marcelo Crespo disserta sobre a história dos crimes digitais no Brasil. O jurista nos apresenta um excelente panorama das diversas modalidades de delitos desta natureza no cenário contemporâneo. Ele também procura desconstruir a percepção amplamente compartilhada, segundo a qual não existem leis eficientes para punir os crimes digitais no Brasil. O autor apresenta as inúmeras ilegalidades enquadradas nesta categoria e demonstra como tais delitos “(...) já eram crimes constantes do ordenamento jurídico brasileiro, apesar dos meios tecnológicos empregados" (p. 416). Ou seja, o Brasil está apto a punir a maioria dos crimes digitais com base no Código Penal vigente criado em 1940. O jurista também postulou que o cerne do problema em torno da punição não é a insuficiência ou caráter das leis existentes, mas sim as condições estruturais para executá-las.

No último capítulo da obra, Sérgio Adorno e Camila Nunes Dias atualizam o debate em torno do sistema prisional. Os sociólogos procuram evidenciar que os modelos teóricos clássicos tornaram-se insuficientes para explicar a complexa dinâmica de funcionamento das cadeias na atualidade, caracterizadas pelo entrelaçamento de atores, mercadorias e serviços dentro e fora dos estabelecimentos penitenciários. Assim, eles esboçam os principais paradigmas explicativos da "sociologia das prisões" para demonstrar a predominância de uma percepção comum entre essas teorias: a ideia de que o 
espaço prisional e a sociedade mais ampla são universos estanques e dicotômicos, rigidamente delimitados física, moral, social, política e culturalmente.

Este modelo hegemônico influenciou enormemente os cientistas sociais brasileiros durante toda a segunda metade do século XX. Todavia, nos últimos anos, importantes transformações tecnológicas e sociais modificaram radicalmente a relação entre o mundo prisional e a sociedade, tornando o paradigma clássico inapropriado para abordar este tema, pelo menos no Brasil. Segundo os autores, dois fatores foram preponderantes para tal modificação: o desenvolvimento dos meios de comunicação e o surgimento do crime organizado. $\mathrm{O}$ acesso aos aparelhos celulares dentro dos presídios, por exemplo, possibilitou o “(...) estabelecimento de vínculos duradouros entre indivíduos e grupos situados dentro e fora da prisão e a constituição de redes sociais consistentes" (p. 455). Desde então, estes universos sociais passaram a se influenciar reciprocamente.

Procuramos descrever sucintamente os aspectos essenciais abordados nos dezesseis capítulos que compõem a obra História dos crimes e da violência no Brasil. Contudo, ainda é necessário refletirmos criticamente se o conteúdo apresentado na coletânea está em consonância com o título e o fio condutor indicado pelas autoras. Conforme mencionamos, para elas "O fio condutor está centrado na ideia de como o crime e o emprego da violência fizeram e fazem parte da nossa sociedade" (p. 8).

Ao examinar os capítulos do livro e suas respectivas temáticas, percebe-se certa coerência nesta assertiva, na medida em que se verifica de fato a existência de várias modalidades de crimes e de práticas violentas perpassando toda a história do Brasil. Entretanto, não podemos consentir inteiramente com a ideia de que a perenidade destes fenômenos apontada pelas autoras constitua por si só um fio condutor. Isso porque a obra não dispõe de nenhum capítulo dedicado a uma discussão historiográfica mais abrangente, capaz de explicar o encadeamento de todos os eventos narrados e/ou também apresentar teorias gerais para se pensar os fatores da criminalidade e da violência.

Além disso, a compreensão da criminalidade no Brasil demandaria necessariamente uma abordagem mais crítica sobre o papel do Estado na criminalização do comportamento social. Seria preciso verificar em que medida a preservação de uma ordem social pacífica, em diferentes conjunturas, atendia aos interesses das elites. Ou, de que maneira a legislação penal vigente refletia as demandas dos estratos dominantes, como a vigilância e o controle dos segmentos subalternos. E, também, como as autoridades estatais deixavam impunes ou, no limite, aplicavam punições mais brandas aos 
membros dos grupos dirigentes. Na direção contrária, caberia ainda, problematizar o viés interpretativo clássico, que relaciona criminalidade e pobreza, tal como fez o sociólogo Michel Misse. ${ }^{2}$

Por outro lado, não obstante os limites que apontamos, a coletânea oferece contribuições fecundas ao campo historiográfico, entre as quais, destacamos três. Em primeiro lugar, o simples fato de tratar de uma temática que, no limite, recebeu pouca atenção da historiografia nacional, sendo mote privilegiado das ciências sociais. Em segundo lugar, deve-se valorizar seu caráter interdisciplinar, pois as autoras selecionaram pesquisadores de diferentes áreas, que produziram estudos de reconhecida qualidade e de extrema atualidade. Por fim, ligado a isso, a investigação de um conjunto de crimes e atos violentos situados em diversos espaços e temporalidades, proporciona ao leitor uma perspectiva multifocal ampliada para abordar esses fenômenos sociais e históricos.

\section{Referência bibliográfica}

MISSE, Michel. Crime e violência no Brasil contemporâneo. Rio de Janeiro: Lumen Juris, 2006.

Recebido: 15/02/2018 - Aprovado: 25/06/2018

2 MISSE, Michel. Crime e violência no Brasil contemporâneo. Rio de Janeiro: Lumen Juris, 2006, p.14-18. 